\title{
Completion of the Manufacturing of the ATLAS Barrel Toroid Magnet at CERN
}

\author{
P. Vedrine, J. M. Rey, G. Volpini, F. Alessandria, M. Arnaud, C. Berriaud, M. Carty, A. Dudarev, B. Levesy, \\ C. Mayri, Y. Pabot, Z. Sun, H. ten Kate, and Y. Zaitsev
}

\begin{abstract}
The last two years have seen the completion of the integration and the cryostating of 8 superconducting coil windings for the ATLAS Barrel Toroid air-core magnet (BT). The Barrel Toroid is a $20 \mathrm{~m}$ in diameter, $25 \mathrm{~m}$ long and $5 \mathrm{~m}$ wide superconducting magnet for ATLAS, one of the two experiments dedicated to the search of the Higgs boson, which will be installed on the LHC ring at CERN in 2006. The paper presents the last steps of this integration progress which ends with the cold acceptance tests. A special emphasis is put on the integration of the cold mass into the vacuum vessel. The integration of the windings in their coil casings has been completed in October 2003 and the last coil cryostating was performed in June 2005. The BT coils are now being installed in the ATLAS cavern at CERN.
\end{abstract}

Index Terms-ATLAS magnet system, superconducting, toroidal coil.

\section{INTRODUCTION}

$\mathbf{T}$ HE Barrel Toroid Magnet is part of the Magnet System [1] of the ATLAS detector for the LHC. The toroidal magnetic field is produced by eight superconducting coils assembled over a length of $25 \mathrm{~m}$ with an inner bore of $9 \mathrm{~m}$ and an outer diameter of $20 \mathrm{~m}$, representing a total weight of $832 \mathrm{t}$. The Barrel Toroid Magnet is the largest superconducting magnet, in size, ever built and represents a major technological challenge. CEA-Saclay originated the design of this magnet and was later responsible for the detailed engineering design and follow-up of the manufacturing of most of the components. INFN Milano, LASA, had also a strong involvement in the design and was responsible of the in-kind delivery for half of the conductor and for all the windings and thermal shields. This work was performed following a collaboration agreement with CERN/ATLAS with a strong support of the ATLAS magnet group.

The last operations of the individual coil manufacturing and integration have been completed in July 2005 at CERN and this paper describes some of them in detail as well as the manufacturing of the cryoring elements which distribute the electrical and cryogenic fluids around the full toroid assembly.

Manuscript received September 19, 2005. This work is part of the ATLAS Detector program on the LHC and are financed for the major part by the ATLAS Collaboration that includes about 145 institutes in 34 countries.

P. Vedrine, J. M. Rey, M. Arnaud, C. Berriaud, M. Carty, B. Levesy, C. Mayri, Y. Pabot, Z. Sun, and Y. Zaitsev are with the CEA Saclay, DSM/DAPNIA, 91191 Gif sur Yvette, France (e-mail: vedrine@ dapnia.cea.fr).

G. Volpini and F. Alessandria are with INFN Milano, LASA, 20090 Segrate, Italy.

A. Dudarev and H. ten Kate are with ATLAS Magnet Team at CERN, 1211 Geneva 23, Switzerland.

Digital Object Identifier 10.1109/TASC.2006.871349

\section{Summary OF THE MAIN COMPONENTS}

The main components have been already described in a previous paper [1] and some of them are detailed in [2]-[5].

In brief, the conductor $(12 \mathrm{~mm} \times 57 \mathrm{~mm})$ is a pure aluminum stabilized cable obtained by a co-extrusion process from a Rutherford-type NbTi cable of large size. The conductor critical current is $58 \mathrm{kA}$ at $4.2 \mathrm{~K}$ and $5 \mathrm{~T}$ [3]. This conductor is then used to wind and vacuum-impregnate with epoxy resin 16 double pancakes [4]. The coil casing is the winding mechanical structure and is made by an assembly of MIG-welded large 5083 aluminum alloy beams. This cold mass is supported inside the vacuum vessel by 8 tie rods and 32 cryogenic stops [5], [6]. The tie rods are made of Ti5Al2.5Sn ELI grade titanium alloy and the cryogenic stops are manufactured with glass-epoxy tubes designed in two parts which allow the $45 \mathrm{~mm}$ sliding of the cold mass with respect to the vacuum vessel during the cool down. Aluminum thermal shields wrapped up with Multi-Layer Insulation (MLI) are placed around the cold mass before the final integration. Cooling circuits made with aluminum and stainless steel pipes thermalized the coil casing at $4.5 \mathrm{~K}$ and the thermal screens at $60-80 \mathrm{~K}$ by conduction cooling.

\section{ASSEMBLING OF THE COLD MASS}

This operation consists in the insertion of the two impregnated double pancake windings in the coil casing and in the subsequent pre-stressing operation, required in order to avoid shear effects at the winding/casing interface during energizing. This is detailed elsewhere [7].

\section{THERMAL SHIELD INSTALlation ON THE COLD MASS}

The 8 thermal shields were manufactured and installed at CERN by E. Zanon SpA (Schio (VI), Italy).

Each shield is composed of 22 independent sections made out of $3003 \mathrm{H} 22$ aluminum alloy sheets $5 \mathrm{~mm}$ thick. Each section is connected to the cold mass by 9 to 17 supports, including the cryogenic stops.

These supports must, under normal and fault conditions, bear the loads and at the same time they must comply with the relative displacement introduced by the difference in thermal contraction between cold mass and the shield, which can reach about 6 $\mathrm{mm}$.

The two cooling circuits, the main and the spare, are composed of $\mathrm{Al}$ pipes, through which $\mathrm{GHe}$ at $40 \mathrm{~K}$ and at a maximum pressure of 20 bar is circulated, welded on two opposite 


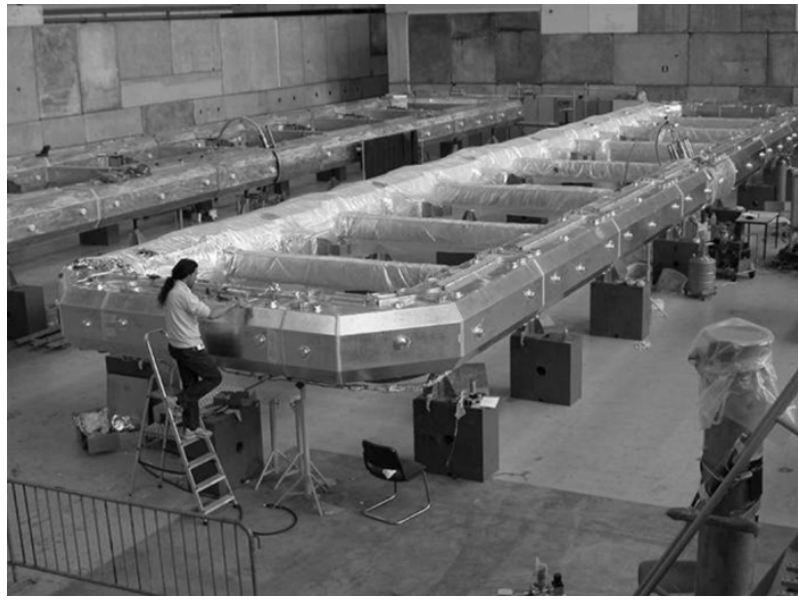

Fig. 1. Integration activities in progress at CERN: in the foreground the shield has been completed and the multilayer superinsulation has been laid on its left side.

faces of the shield. The GHe is distributed to the Al pipes by means of stainless steel manifolds.

The shield integration activities were organized as follows.

a) The first step was the installation and the proper alignment of the shield sections with respect to the cold mass, before the installation of the supports. The small clearance available between the shield and the vacuum chamber (less than $35 \mathrm{~mm}$ at some locations, mostly occupied by the MLI) and the manufacture dimensional tolerances of the shield and of the vacuum chamber called for accuracy of positioning of few $\mathrm{mm}$. Vertically (here and afterwards, with respect to the integration position) the alignment was guaranteed within $1 \mathrm{~mm}$ by the provisional supports (see the shield in the background of Fig. 1), and horizontally the shield was adjusted until the optimum position was reached.

b) The Al cooling pipes were welded on the shield.

c) The position of the shield had to be checked again to verify the deformation of the panels introduced by the welding. Normally only vertical deformations smaller than $3 \mathrm{~mm}$ were found, so that no further modification of the panels was required.

d) The installation of the supports could then start. The supports' Permaglas tubes, resting on the cold mass, were pre-stressed by means of thread rods of a similar fiberglass material in order to provide contact under any circumstance between the tubes and the surface of the cold mass. The pre-stress was repeated so as to reintroduce most of the stress lost because of creep phenomena. The external caps of the supports (see Fig. 2), connecting the tubes to the shield were then installed.

e) The stainless steel manifolds were mounted and welded to the transition joints. The reliability of the cooling system represents probably the most critical issue of the whole shield installation. The length and the number of curves of the circuit, the presence of both aluminum pipes welded to the panels and of stainless steel manifolds for the distribution of the coolant to all the circuits, the number of welds both on aluminum and on stainless steel, the use

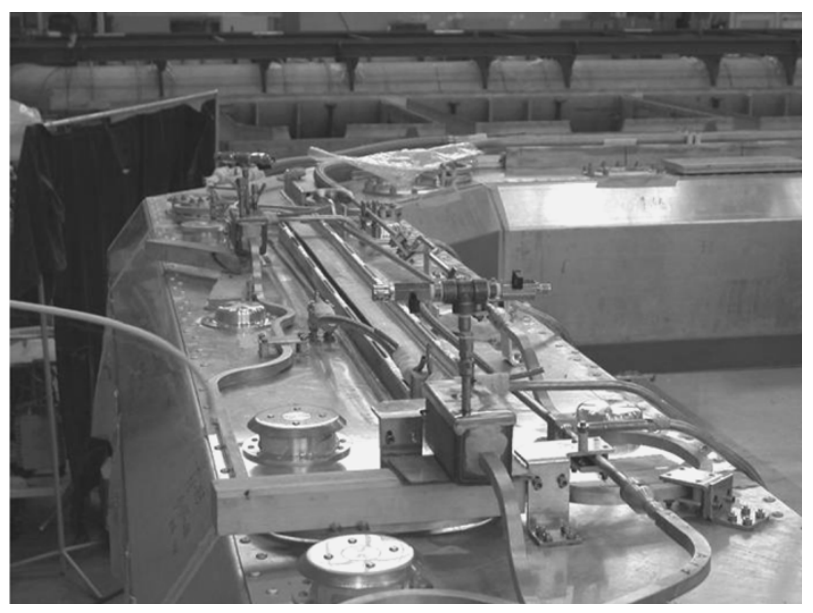

Fig. 2. Top view of the short side of one thermal shield, after completion of the installation of all the components. We see the $\mathrm{Al}$ cooling lines (square pipes) welded to the shield, the stainless steel distribution manifolds (circular pipes), and the caps of the supports connecting the shield to the cold mass. Two of boxes used for the "thermal shock test" (see text), are visible on their wood supports.

of stainless steel to aluminum transition joints, the very demanding specified maximum leak rate, $4 \cdot 10^{-9} \cdot \mathrm{Pa}$. $\mathrm{m}^{3} \cdot \mathrm{s}^{-1}$, and the fact that no access will be available after the vacuum vessel closure, all these factors called for the highest level of reliability. For these reasons, the most difficult $\mathrm{Al}$ welds were performed during the pre-manufacture stage, leaving only stainless steel welds to be done during the integration. All the welds performed during the assembly at CERN were X-rayed and certified to the highest standard, namely UNI EN 25817 level B, as foreseen by Technical Specification. After completing all the assembly operations, the full extension of the two cooling circuits (main and spare) were subject to leak test by aspersing Helium gas, after performing on all the welds and on the transition joints a so-called "thermal shock test", a fast cool down to liquid nitrogen temperature. No evidence of leaks was found up to the sensitivity of the test, limited by the background which ranged from 1 to several $10^{-10} \mathrm{~Pa} \cdot \mathrm{m}^{3} \cdot \mathrm{s}^{-1}$.

\section{Insertion of the Cold Mass Into the Vacuum VesSel}

The vacuum vessel is a $25 \mathrm{~m}$ long racetrack tube of $1100 \mathrm{~mm}$ in diameter, sliced in two half shells. It consists of $10 \mathrm{~mm}$ thick plates made from a $304 \mathrm{~L}$ stainless steel alloy rolled and welded.

After the thermal shield installation, the cold masses are lowered into the lower half shell and laid on the cryogenic stops, which connect the cold mass to the vessels. The vacuum vessel is then closed with its upper shell and the two halves are welded.

Due to the low stiffness of the cold mass, great care had to be taken for all the handling operations. This motivated the design of a high inertia lifting beam able to carry a $100 \mathrm{t}$ coil with less than $5 \mathrm{~mm}$ of bending deflection along its entire length (Fig. 3). This specific tool has been designed and constructed by the JINR workshop in Dubna (Russia).

The insertion of the cold mass inside the vacuum vessel had several critical aspects: 


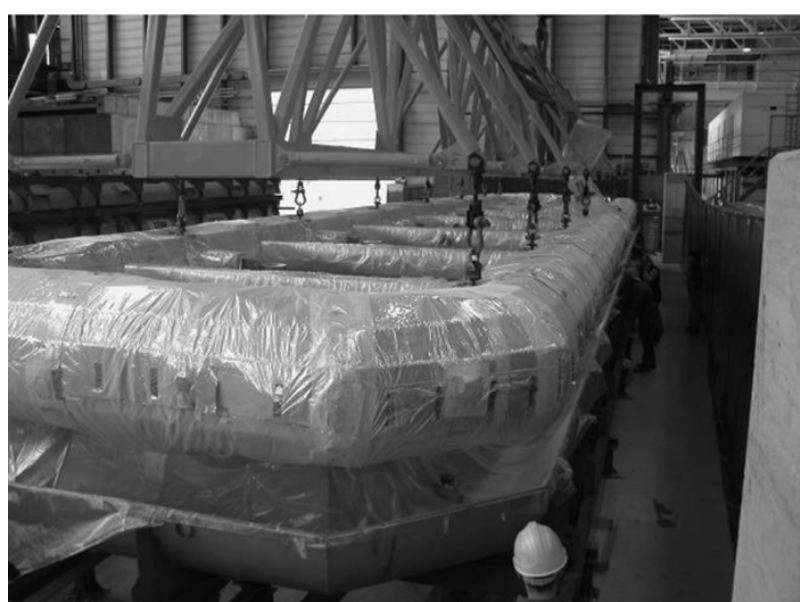

Fig. 3. The cold mass held by the high inertia lifting frame being lowered down in the vacuum vessel. Gaps between the vacuum vessel and the superinsulation are controlled.

- The sharing of the cold mass weight (about $40 \mathrm{t}$ ) between the 16 cryogenic stops had to be thoroughly controlled, to avoid overloading any of them beyond its maximum design value $(60 \mathrm{kN})$.

- The gap between the superinsulated cold mass and the vacuum vessel had to be well balanced in order to avoid any contact between the MLI and the vacuum vessel under any working condition.

- Welding of the tie rods cone, linking the cold masses to the vacuum vessel, had to be controlled precisely to allow the further assembling of the whole toroidal structure.

To deal with the first aspect, a flatness adjustment of the upper faces of the cryogenic stops would not have been sufficient, mainly because of two reasons: first, the flatness of the cold mass is not known with the precision that would be required, few tenths of $\mathrm{mm}$, which is not easy to achieve on lengths of $25 \mathrm{~m}$. Second, since the bending stiffness of the cold mass $(70 \mathrm{kN} / \mathrm{mm})$ is close to the stiffness of the cryogenic stops $(100 \mathrm{kN} / \mathrm{mm})$, any error on the adjustment of the height of one stop would have induced changes on the loading of the nearest stops, and their potential overloading.

The theoretical load on each of the cryogenic stops varies from $16.6 \mathrm{kN}$ to $45 \mathrm{kN}$. So, in order to have a proper load distribution independently of the shape of the cold mass, a special hydraulic insertion device has been developed. This consists of 16 hydraulic jacks, each supporting one of the cryogenic stops during the insertion of the cold mass.

The pressure in the 16 jacks was controlled by means of three independent circuits.

- One circuit included the 8 jacks placed under the central cryostops, where the mean theoretical load was expected.

- Another circuit controlled the jacks under the 4 next cryostops, where the minimum theoretical load was expected (minimum pressure circuit).

- Due to the cantilever effect at the end parts of the cold mass, the highest load is expected in the four cryogenic stops located near the end of the cold mass. The four jacks supporting these stops composed the last circuit.
Each of these circuits had an adjustable relief valve set to the nominal pressure corresponding to the load on the stops. On the minimum pressure circuit, the pressure was set $10 \%$ under the minimum final load to allow the cryogenic stops to rest on adjustable mechanical stops placed on the jacks, which define the final plane of the cold mass. The insertion of the cold mass was then done in steps:

- All the jacks were pulled out to their maximum extension.

- The minimum pressure circuit relief valve was closed.

- The relief valves of the other two circuits were open, set to their nominal values.

- The cold mass was then laid on the cryostops and controls were made to ensure that the gaps were well balanced all around the cold mass.

- At the same time the pressure in the minimum pressure circuit was measured to assess the weight of the cold mass.

- The relief valve of minimum load circuit was then opened, allowing the oil to flow out, and thus reducing the pressure exerted by the jacks.

- As a consequence of this, a load transfer took place, increasing the pressure inside the other circuits, whose relief valves eventually opened. The cold mass started to slowly descend into the vacuum vessel.

- When the hydraulic jacks of the minimum pressure loop came in contact with their mechanical stops the cold mass was in place.

By proceeding in this way the load was controlled on all the highly mechanically loaded cryogenic stops, ensuring the best possible load distribution which kept the cold mass "stress free" and as flat as possible.

Then, the final longitudinal welding of vacuum vessel is performed.

\section{CRYORING MANUfACTURE}

The cryogenic distribution line, also called "cryoring", is divided in 8 sectors, located on the external radius of the toroid magnet and longitudinally near the center. Each sector is $6 \mathrm{~m}$ long. It distributes the electrical power and conveys the cryogenic fluids to the 8 coils. The current goes through superconducting busbars cooled with biphasic helium, coming from the coils, at $4.5 \mathrm{~K}, 1.4$ bar, which circulates through aluminum pipes glued on the busbar mechanical structure. Inside the vacuum vessel, a superinsulated thermal shield cooled with helium gas at $60 \mathrm{~K}, 18$ bar surrounds the busbars. The top sector is linked to the Current Leads Cryostat which includes the current leads and which is a part of the Proximity Cryogenic System [1]. The bottom sector includes a valve box allowing the fluid distribution to the eight coils. Each sector extremity is equipped with a sleeve allowing the connection to the coil after the toroid assembly. The two sleeves contain the electrical joints between the extremities of the coil conductors and the busbar, and all the welds of the pipes of the cooling circuits.

The three types of cryoring sectors were built at Saclay and then delivered to CERN for their final assembly on the toroid. The backbone of the sector is the busbar, (except for the bottom section). The integration (Fig. 4) is done around this item, which is instrumented with thermal sensors, voltage taps and quench detection systems. A special attention has been paid to 


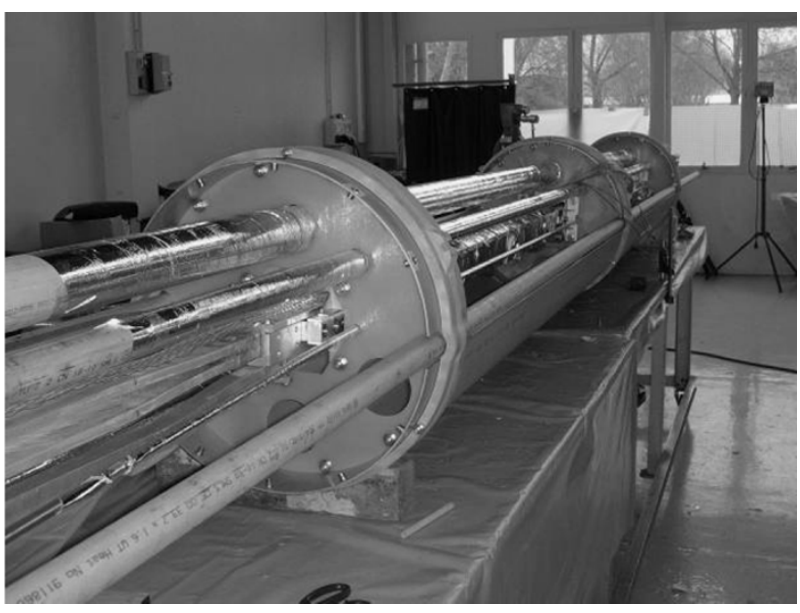

Fig. 4. Cold mass before the assembly of the thermal shields. He tubes are visible as well as the busbar on the center of the assembly.

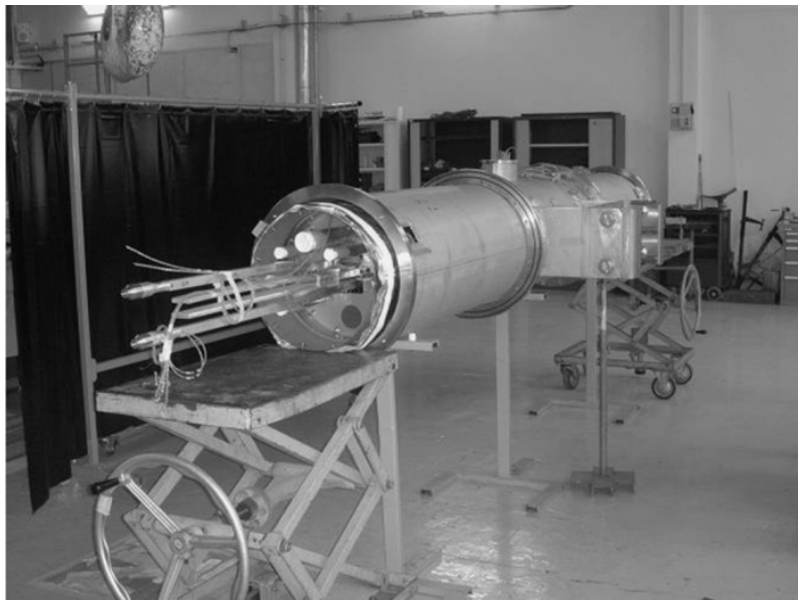

Fig. 5. Cryostated standard sector.

the sliding pads, which must allow the thermal shrinkage of the busbar with respect to the vacuum vessel, and also support the torque generated by the two opposite lines of current in the external magnetic field. After the mounting of the pipes in the spacers, the stainless steel shield and the superinsulation blankets are installed. Then all is inserted into the vacuum vessel and fixed by external welded brackets inserted in the spacer grooves (Fig. 5).

An extensive series of tests and controls was performed: special care was devoted to the busbar electrical insulation, repeated at least three times. All the welds, including those on the bimetallic transitions on the aluminum pipes were X-ray controlled, and thermal shocked, before the leak tests, with criteria analogous to those described in Section IV.

\section{CONCLUSION}

Once closed and welded each cryostat was installed on a test bench located at CERN and tested at $4.5 \mathrm{~K}$ and $22 \mathrm{kA}$ [8], [9]. The eight individual coils were then lowered down a $100 \mathrm{~m}$ deep pit for the final assembly in the ATLAS cavern with the warm structure [10], [11]. The first test of the Barrel Toroid commissioning is foreseen for the beginning of 2006.

The coil integration phase of the ATLAS Barrel Toroid magnet, completed in July 2005, represents an important milestone in the completion of this unique superconducting magnet before its delivery to the ATLAS collaboration and its use in the quest of new particles in high energy physics.

\section{ACKNOWLEDGMENT}

The authors express their warm thanks to all the staff-members of DAPNIA, LASA and CERN, especially to M. Humeau, H. Lannou, R. Leboeuf from CEA, C. Gesmundo, A. Leone, L. Marchetti, D. Pedrini, M. Todero, C. Uva from LASA, and J. Sorokina from CERN.

\section{REFERENCES}

[1] H. ten Kate et al., "The ATLAS superconducting magnet system: status of integration and installation," IEEE Trans. on Applied Superconductivity, submitted for publication.

[2] P. Vedrine et al., "Manufacturing and integration progress of the Atlas barrel toroid magnet," IEEE Trans. Applied Superconductivity, vol. 14, no. 2, pp. 491-494, June 2004

[3] G. Volpini et al., "Production review of $85 \mathrm{~km}$ of Al-stabilized NbTi cable for the ATLAS toroids," IEEE Trans. on Applied Superconductivity, submitted for publication.

[4] G. Drago et al., "Experience report of the manufacture of the $25 \mathrm{~m}$ long superconducting coils for the ATLAS barrel toroidal magnet," IEEE Trans. on Applied Superconductivity, submitted for publication.

[5] C. Mayri et al., "Suspension system of the barrel toroid cold mass," IEEE Trans. on Applied Superconductivity, submitted for publication.

[6] O. P. Anashkin, "Mechanical tests of the ATLAS barrel toroid tie rods," Cryogenics, vol. 45, pp. 469-472, July 2005.

[7] J. M. Rey et al., "Cold mass integration of the ATLAS barrel toroid magnets at CERN," IEEE Trans. on Applied Superconductivity, submitted for publication.

[8] A. Dudarev et al., "On-surface test of the ATLAS barrel toroid coils: overview," IEEE Trans. on Applied Superconductivity, submitted for publication.

[9] C. Berriaud et al., "On-surface test of the ATLAS barrel toroid coils: acceptance criteria and results," IEEE Trans. on Applied Superconductivity, submitted for publication.

[10] A. Foussat et al., "Assembly concept and technology on the ATLAS barrel toroid magnet," IEEE Trans. on Applied Superconductivity, submitted for publication.

[11] Z. Sun, "ATLAS barrel toroid warm structure design and manufacturing," IEEE Trans. on Applied Superconductivity, submitted for publication. 